\title{
DESERT ON THE MENU? WHAT CHILDREN ARE SERVED IN GERMAN FULL-SERVICE RESTAURANTS
}

\author{
Lisa Rüsing ${ }^{1}$, Jennifer Hilger-Kolb², Sven Schneider ${ }^{2}$ \\ ${ }^{1}$ Medical Faculty Mannheim, Heidelberg University, Mannheim, Germany \\ ${ }^{2}$ Mannheim Institute for Public Health, Social and Preventive Medicine, Heidelberg University, Mannheim, Germany
}

\section{SUMMARY}

Objectives: Prevalence of obesity and overweight among children is rising worldwide. Thus, the importance of restaurants as food environments is also growing. Considering these developments, the present study describes and evaluates menus and meals offered to children in German full-service restaurants.

Methods: Using quota sampling procedure, a representative sample of German full-service restaurants was identified. The individual meals were then assessed, using the Children's Menu Assessment tool (CMA). A total of 500 restaurants and 1,877 individual meals were analyzed.

Results: On average, every menu included $3.76 \pm 1.31$ meals for children. The arithmetic mean of the CMA score was $0.73 \pm 0.85$. Around $80 \%$ of all offered meals were limited to eight typical dishes and over $50 \%$ included French fries or another form of fried potatoes. Not one of the meals included any nutritional information. Healthy entrees were never marked (e.g. by an optional qualitative information such as healthy food symbol or a healthier choice tag). Eighty-one percent of all the main components in the meals were rated as unhealthy and none of the meals used wholegrain products. The automatic inclusion of a drink and free refill options are both rather unusual in Germany, as well as the use of cartoon characters and product logos or giving away promotional toys. A positive correlation was found between the price of the food and its quality. The majority of dishes feature a high energy density while simultaneously having a low nutrient density.

Conclusions: Overall, the range of food on offer for children in German restaurants is unhealthy and lacking in variety. There is an urgent need for improvement of both the menus themselves as well as the offered meals. Our study is not only by far the most comprehensive study, but also the study with the worst CMA score values worldwide.

Key words: paediatric obesity, child health, meals, restaurants, environment

Address for correspondence: S. Schneider, Division Head Child \& Health, Medical Faculty Mannheim, Heidelberg University, Mannheim Institute of Public Health, Social and Preventive Medicine, Ludolf-Krehl-Straße 7-11, D-68167 Mannheim, Germany. E-mail: sven.schneider@medma. uni-heidelberg.de

https://doi.org/10.21101/cejph.a5878

\section{INTRODUCTION}

Today, our modern lifestyles only require a minimal amount of physical activity and cheap, calorie-dense foods can be found just about everywhere (1). As a consequence of this, the proportion of people in the global population who are overweight is increasing dramatically: Excess weight and juvenile obesity in particular are among the most serious public health problems currently faced in developed countries. For example, around $15 \%$ of children and adolescents aged 3-17 in Germany today are classed as overweight, of which $6 \%$ are classed as obese (2). Within just 20 years, the prevalence of overweight and obese adolescents has thus doubled or tripled respectively $(2,3)$.

From a medical point of view, there is a general consensus that the early years in a child's life are the most appropriate time to target obesity prevention (4). Following the lack of success of individual-focused and educational intervention programmes (e.g. diets, nutrition and exercise programmes) which have dominated for so long at a national level, current public health research is increasingly turning to look at so-called contextual factors (4). In this context, the term "food environments" has become estab- lished (5), Rideout et al. define the food environment as the sum of all physical, social, economic, cultural, and political factors that impact the accessibility, availability, and adequacy of food within a community or region (5).

Given their growing sales figures, restaurants are considered to be important food environments $(6,7)$. Families are cooking less frequently at home, instead, it is becoming more and more common to consume main meals outside of the home. This development has seen turnover in the US restaurant industry quadrupling in the last 30 years (8). Parallel to this, the daily caloric intake of American children from food eaten outside the home increased from $23 \%$ in 1977 to 34\% in 2006 (9). The same development has also been observed in Europe and in Germany in particular (10), where revenues have shown continuous growth for many years at a rate of $3.4 \%$ (11). According to industry data, it is becoming increasingly common for families in particular to eat out at restaurants (12). Yearly more than 2 billion visits in Germany indicate why fullservice restaurants in particular are an innovative and potentially significant approach for improving food environments $(7,13)$.

Almost all previous research in this field comes from North America, particular in relation to so-called kid's menus or 
children's meals $(9,14,15)$. These studies show that restaurant foods are often higher in calories and lower in nutritional value than foods prepared at home (15). It is therefore no wonder that several prospective studies among adults and adolescents have demonstrated that frequently eating in restaurants is correlated with excess weight gain over time (16). More specifically, the frequency of eating outside the home in restaurants is associated with increased average caloric and saturated fat intake, and lower fruit, vegetable, calcium, and fiber consumption $(14,16,17)$.

Unlike in the USA, fast food and chain restaurants play a much less influential role in Europe: in Germany, these types of restaurant only make up $24 \%$ of total restaurant sales (18). Instead, owneroperated restaurants have always dominated the German market. In addition to the less widespread distribution of restaurant chains, there are also cultural reasons behind why families in particular are more likely to go to an independent, owner-operated restaurant than a chain for their lunchtime or evening meal.

In light of the limited transferability of research findings from North America to other national - in this case, German - contexts, the present study aims to examine the range of foods available for children and adolescents in German full-service-restaurants in terms of presentation, price, composition and preparation, as well as the nutritional quality of these meals.

\section{MATERIALS AND METHODS}

\section{Data Sample}

With 83 million inhabitants, Germany is the largest country in the European Union; it is a federal republic that is divided into 16 federal states. In order to obtain a representative picture of the range of food available for children in Germany, the first step of the "Kids' meals in Germany" (KinG) study was to obtain a nationwide sample of restaurants using systematic quota sampling. This process involved first calculating the quotas - i.e. the number of restaurants per federal state that needed to be included in the study - for a total sample size of 500 restaurants on the basis of official tax records (19). The authors present more details of the study design and first preliminary results in their work (19). The relevant tax statistics for the last available year at the time that the sampling was done included the number of businesses listed under 'Gastronomy' (restaurants with and without accommodation in 2015) per federal state.

Following the calculation of the quotas to be observed, sampling took place between 1 June and 12 June 2017 using the Google Search online search engine to identify enough restaurants until the previously established quotas for each federal state had been reached. In order to avoid a bias caused by user data or online advertising, the selection was carried out without logging into a Google user account and without looking at any recommended links or paid advertisements. Next, the website of each hit was visited in order to check the following inclusion and exclusion criteria.

\section{Inclusion and Exclusion Criteria}

Identifying the restaurant: The sample included individual fullservice restaurants with table service (sit-down restaurants) (14), who had an online menu that explicitly included a children's menu. The section of the menu was required to be clearly identifiable, i.e. with a heading such as "For our younger guests", "Children's menu" or "Kids' meals". Fast food or chain restaurants were excluded from the sample (e.g., McDonalds, Burger King or other chains), as were restaurants where food was only available for takeaway. The identified menus, including the restaurant address, were archived in paper format and digitally as a PDF file.

Identifying the children's menus: Within the restaurant's menus, all children's meals were identified and their specific description was transcribed in full (e.g., ID 13_4 "Chicken nuggets with fries, ketchup or mayonnaise"; ID57_5 "Pizza margarita with cheese and tomato sauce"; ID 110_3 "Spaghetti with creamy mushroom sauce"). Starters and desserts were only included in the evaluation if such components were part of a combination with a main meal (e.g. ID 286_2 "Breaded turkey escalope with vegetables and fries and an ice cream").

\section{Assessment Procedure}

For each restaurant, a record was made of the number and price of the children's meals on the menu and the address and post code of the restaurant. A note was also made indicating whether the restaurant also offered any type of accommodation (e.g. hotels, motels or bed and breakfasts) and whether the meal is served as part of a buffet.

The individual meals were then assessed using the Children's Menu Assessment (CMA) tool (20). In contrast to other tools (14) the Children's Menu Assessment was specifically developed to evaluate the food environment in restaurants for children in particular. Developed in the USA, this scoring system consists of 21 scored items and a number of other descriptive items. These 21 items are originally derived from government recommendations for a healthy diet (e.g., US Food and Drug Administration, US Department of Health and Human Services, US Department of Agriculture) and evaluate individual aspects of a meal in terms of whether it is perceived to be healthy or unhealthy by the abovementioned institutions. The Children's Menu Assessment tool comes with very detailed completion instructions, which were adhered to stringently while conducting this study. According to the Children's Menu Assessment, entrées are considered unhealthy if they are fried (e.g. fried chicken wings). However, if an entrée comprises baked or broiled meat (other than red meat) or steamed or grilled vegetables, then it is rated as healthy. The individual items are to be taken together with the score value from Table 1 and then added together, resulting in a total score with a value range of -5 to +21 . The higher the CMA score value, the healthier the meal is rated (20). The CMA features a high degree of inter-rater reliability $(0.90)$ and a similarly high test-retest reliability level (0.96) (20).

It is very rare for complete menu combinations to be offered in Germany, so that the child or their parents can put together a multi-course meal made up of different components. These types of menu combinations, offered as 'kids' meals' or 'kids' menus', are mainly offered by fast food or chain restaurants (like in the USA, where the CMA was developed), which were not included in our study. As a rule, a children's meal in Germany only comprises a main meal; it is very rare for a drink or dessert to be included automatically. This meant that the methodological problem that is 
typically encountered in the USA, whereby numerous variants of a menu can be put together from the individual components, some of which may be unhealthy and some of which may be healthy, was therefore not encountered in our region of study, Germany. Therefore, for example, the original item "healthy salad" $(\geq 1$ healthy entrée salads $=2$ points, 0 healthy entrée salads $=0$ points) was operationalized in such a way that two points were awarded if the children's meal was a healthy salad and zero points were awarded if it was not a healthy salad. Likewise, the same procedure was applied for the items "healthy entrée", "healthy dessert" and "wholegrain". Before it was applied to the original data set, the German version of this assessment, as translated by the second author J H-K (qualified dietician), was tested by SS and LR for inter-rater reliability (0.88) and test-retest reliability (0.93).

\section{Validation Procedure}

In order to validate the database, a second nationwide sample was created in order to quantify how many restaurants do not make their menu available online $(n=100)$. In addition to this, other standard quality control measures (plausibility checks, double coding, checking extreme values) were carried out.

\section{Statistical Methods and Ethics Vote}

The statistical analysis first comprised a classic descriptive evaluation based on the number of restaurants and the meals on the menu. For correlative analyses at a restaurant level, the average price of the children's meals offered and the average score from the Children's Menu Assessments were determined for each restaurant. Pearsons correlation coefficient was used to measure linear correlation. All analyses were conducted using IBM SPSS Statistics 24 (IBM Corp., Armonk, USA) using a predefined level of significance of $\mathrm{p}<0.05$.

The ethics committee responsible confirmed to us that, in accordance with current laws, an ethics vote was not required for the study design, as the study does not work on or with people or their data*.

\section{RESULTS}

On average, every menu included $3.76 \pm 1.31$ meals for children. The average price was $€ 5.51 \pm € 1.41$ (as of 1 July 2019, this is equal to $\$ 6.22 \pm \$ 1.59$ or $£ 4.92 \pm £ 1.26$ ). Three-quarters of the 500 restaurants studied were typical full-service restaurants, while the remaining restaurants were full-service restaurants with a hotel or other lodgings. None of the 500 restaurants studied specifically offered children's food as a buffet; instead, the selected dish was served at the table (Table 1).

A total of 1,877 meals were recorded from 500 menus. However, around $83 \%$ of the meals were limited to eight typical dishes (Fig. 1). More than a quarter of all children's meals consisted of a variant of chicken nuggets with French fries (29\% of all meals). This category also included variants of breaded meat in different
Table 1. Characteristics of restaurants and children's menus included in the KinG study, Germany $(N=500)$

\begin{tabular}{|c|c|c|}
\hline Variable & $\begin{array}{c}\text { Absolute frequency } \\
n\end{array}$ & $\begin{array}{c}\text { Relative frequency } \\
\%\end{array}$ \\
\hline \multicolumn{3}{|l|}{ Descriptive data } \\
\hline \multicolumn{3}{|l|}{ Number of children's meals } \\
\hline $1-2$ & 71 & 14.2 \\
\hline 3 & 163 & 32.6 \\
\hline 4 & 137 & 27.4 \\
\hline $5-9$ & 129 & 25.8 \\
\hline Price of meal (€) & *5.51 (1.41) & $* * 1.0-18.0$ \\
\hline \multicolumn{3}{|l|}{ Accommodation option } \\
\hline With accommodation & 129 & 25.8 \\
\hline Without accommodation & 371 & 74.2 \\
\hline \multicolumn{3}{|l|}{ Way of ordering } \\
\hline Ordering a single meal & 500 & 100.0 \\
\hline Buffet & 0 & 0.0 \\
\hline
\end{tabular}

${ }^{*}$ Arithmetic mean (Standard deviation); **Range

shapes, which were usually deep-fried (also referred to as chicken crossies, schnitzel sticks, chicken crispies) and always served in combination with deep-fried potato products. One in five meals comprised pasta with sauce (e.g., cream sauce, ham and cream sauce, tomato sauce). The third most common meal offered for children was French fries offered as a meal on their own, without any other meat or vegetable component. French fries were also very common $(45.7 \%)$ as a side dish in the category "Other meals". In total, this meant that $54.2 \%$ of the 1,877 meals included French fries or another form of fried potatoes, e.g., potato twisters, potato wedges, fried potatoes, potato chips, potato spirals (Fig. 1).

Where fish was offered, this was almost always breaded fish sticks. Combined with a few individual cases of "breaded fish fillet", these made up $7.7 \%$ of all meals $(n=144)$ (Fig. 1). There were only 31 cases where fish was offered in a different form, which were nearly all children's portions of breaded and fried squid rings (calamari). Ocean perch, redfish and plaice (saltwater fish with a low to medium fat content) as well as pike-perch and pike (freshwater fish) were each offered in one restaurant, respectively. Two occurrences of real salmon and cod (fatty fish), respectively, were found on the children's menus. These 31 cases were included in the category "Other dishes". In total, three out of ten restaurants included at least one fish option on their children's menu. However, no pattern - no accumulation at the coasts, rivers or lakes - could be clearly identified from the regional distribution of fish dishes (Fig. 2). The same applies to the regional distribution of the other dishes represented in Figure 1 (not represented cartographically).

In the next step, the individual items from the CMA allowed for a more differentiated, nutritional evaluation of the meals available; the CMA determines nutritional guidance. In fact, not one of the meals recorded included any kind of nutritional infor-

*Written message to the first author from Prof. Dr. Striebel, Chairman of Ethics Committee II of the Mannheim Medical Faculty, Heidelberg University, Germany, dated June 20, 2018. 


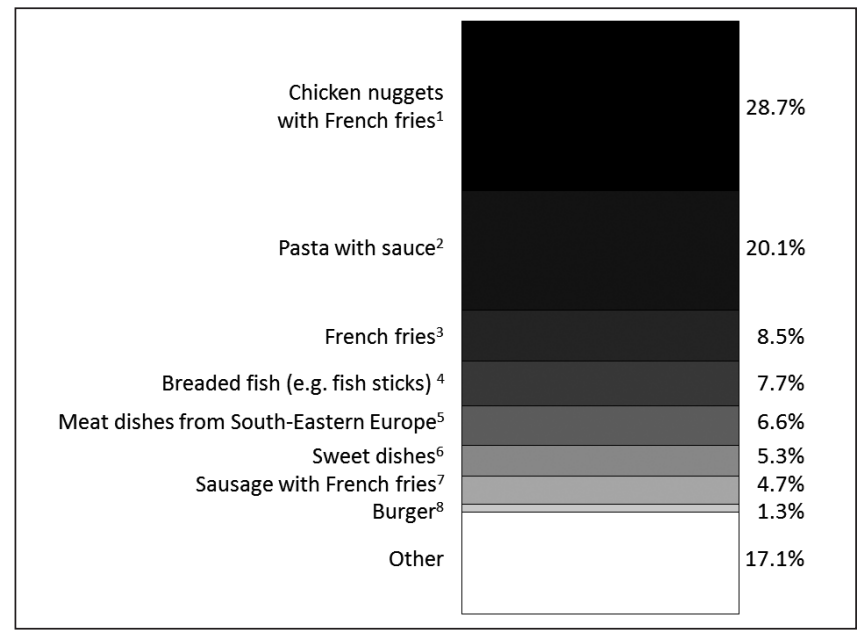

Fig. 1. Meals most commonly found on children's menus in restaurants included in the KinG study, Germany.

${ }^{1}$ Also includes other variants of breaded muscle meat in different shapes, which were usually deep-fried (also referred to as chicken crossies, schnitzel sticks, chicken crispies) and always served in combination with deep-fried potato products.

${ }^{2}$ Includes lasagna.

${ }^{3}$ French fries or any other form of fried potatoes (twisters, potato wedges, fried potatoes, potato chips, potato spirals) with or without ketchup, mayonnaise or another sauce and without any other side dish.

${ }^{4}$ Always served with French fries or another form of fried potatoes.

${ }^{5}$ Usually served with French fries or another form of fried potatoes.

${ }^{6}$ Semolina pudding, rice pudding, hash browns etc., always served with a sweet side

(e.g. nut-nougat spread, cream, chocolate sauce, jelly).

${ }^{7}$ Or another form of fried potatoes.

${ }^{8}$ Includes a side dish (e.g. French fries) in some cases.

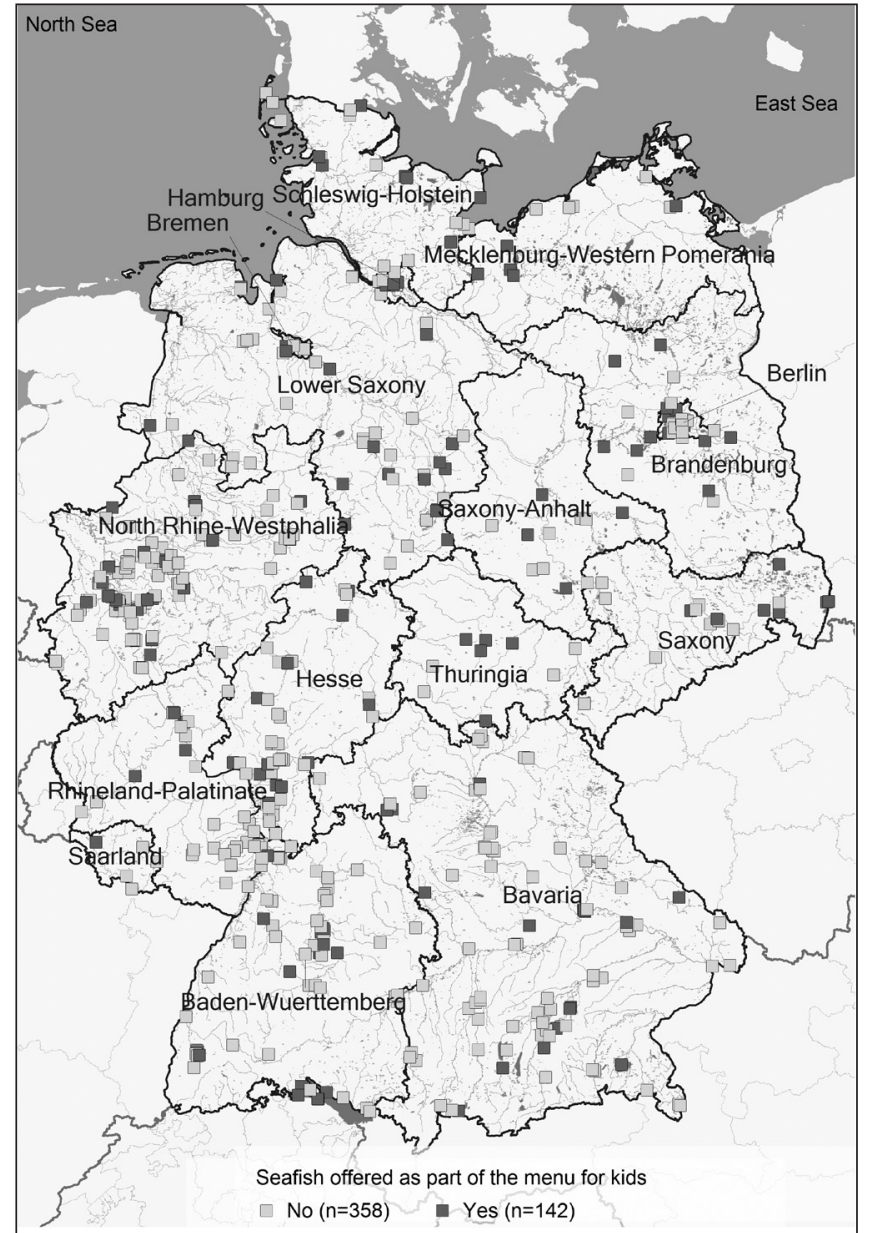

Fig. 2. Map of all restaurants included in the KinG study, Germany (by sea fish offered as part of the menu for kids).
Table 2. Assessment of children's menus found in the KinG study, Germany, based on Children's Menu Assessment tool $(N=1,877)$

\begin{tabular}{|l|l|c|c|}
\hline Variable & Score-value & $\begin{array}{c}\text { Absolute } \\
\text { frequency } \\
\mathrm{n}\end{array}$ & $\begin{array}{c}\text { Relative } \\
\text { frequency } \\
\%\end{array}$ \\
\hline
\end{tabular}

\section{Nutrition guidance}

Any nutrition information

\begin{tabular}{|c|c|c|c|}
\hline Yes & 2 & 0 & 0.0 \\
\hline No & 0 & 1,877 & 100.0 \\
\hline \multicolumn{4}{|l|}{ Indicating healthy item (e.g. by a symbol) } \\
\hline Yes & 1 & 0 & 0.0 \\
\hline No & 0 & 1,877 & 100.0 \\
\hline
\end{tabular}

\section{Entrées}

Healthy entrée

\begin{tabular}{|l|c|c|c|}
\hline Yes & 2 & 357 & 19.0 \\
\hline No & 0 & 1,520 & 81.0 \\
\hline
\end{tabular}

Healthy entrée salad

\begin{tabular}{|l|c|c|c|}
\hline Yes & 2 & 10 & 0.5 \\
\hline No & 0 & 1,867 & 99.5 \\
\hline
\end{tabular}

Any whole grains

\begin{tabular}{|c|c|c|c|}
\hline Yes & 2 & 0 & 0.0 \\
\hline No & 0 & 1,877 & 100.0 \\
\hline
\end{tabular}

\section{Side dishes}

\begin{tabular}{|c|c|c|c|}
\hline \multicolumn{4}{|l|}{ Non-fried vegetables/salad } \\
\hline Yes & 2 & 644 & 34.3 \\
\hline No & 0 & 1,233 & 65.7 \\
\hline Healthy salad dressing & \\
\hline Yes & 1 & 0 & 0.0 \\
\hline No & 0 & 1,877 & 100.0 \\
\hline
\end{tabular}

Any fruit

\begin{tabular}{|c|c|c|c|}
\hline Yes & 1 & 90 & 4.8 \\
\hline No & 0 & 1,787 & 95.2 \\
\hline
\end{tabular}

Fruit without added sugar

\begin{tabular}{|l|c|c|c|}
\hline Yes & 1 & 1 & 0.1 \\
\hline No & 0 & 1,876 & 99.9 \\
\hline
\end{tabular}

Dairy side dish

\begin{tabular}{|l|c|c|c|}
\hline Yes & 1 & 243 & 12.9 \\
\hline No & 0 & 1,634 & 87.1 \\
\hline
\end{tabular}

Low-fat dairy side dish

\begin{tabular}{|l|c|c|c|}
\hline Yes & 1 & 0 & 0.0 \\
\hline No & 0 & 1,877 & 100.0 \\
\hline \multicolumn{4}{|l|}{ Opportunity for healthier side substitution } \\
\hline Yes & 1 & 100 & 5.3 \\
\hline No & 0 & 1,777 & 94.7 \\
\hline
\end{tabular}

Continued on the next page 
Continued from the previous page

\begin{tabular}{|c|c|c|c|}
\hline Variable & Score-value & $\begin{array}{c}\text { Absolute } \\
\text { frequency } \\
n\end{array}$ & $\begin{array}{c}\text { Relative } \\
\text { frequency } \\
\%\end{array}$ \\
\hline \multicolumn{4}{|c|}{ Beverages } \\
\hline \multicolumn{4}{|c|}{ Juice listed as $100 \%$ juice } \\
\hline Yes & 1 & 1 & 0.1 \\
\hline No & 0 & 1,876 & 99.9 \\
\hline \multicolumn{4}{|c|}{ Low-fat milk } \\
\hline Yes & 1 & 0 & 0.0 \\
\hline No & 0 & 1,877 & 100.0 \\
\hline \multicolumn{4}{|c|}{ Soda targeted at children } \\
\hline Yes & -1 & 10 & 0.5 \\
\hline No & 0 & 1,867 & 99.5 \\
\hline \multicolumn{4}{|c|}{ Free soda refills for children } \\
\hline Yes & -1 & 0 & 0.0 \\
\hline No & 0 & 1,877 & 100.0 \\
\hline \multicolumn{4}{|c|}{ Opportunity for healthier beverage substitution } \\
\hline Yes & 1 & 1 & 0.1 \\
\hline No & 0 & 1,876 & 99.9 \\
\hline \multicolumn{4}{|l|}{ Desserts } \\
\hline \multicolumn{4}{|c|}{ Healthy dessert included in children's meal } \\
\hline Yes & 1 & 0 & 0.0 \\
\hline No & 0 & 1,877 & 100.0 \\
\hline \multicolumn{4}{|c|}{ Unhealthy dessert included in children's meal } \\
\hline Yes & -1 & 47 & 2.5 \\
\hline No & 0 & 1,830 & 97.5 \\
\hline \multicolumn{4}{|c|}{ Toys/marketing } \\
\hline \multicolumn{4}{|c|}{ Marketing toward children } \\
\hline Yes & -1 & 4 & 0.2 \\
\hline No & 0 & 1,873 & 99.8 \\
\hline \multicolumn{4}{|c|}{ Toy included with children's meal } \\
\hline Yes & -1 & 7 & 0.4 \\
\hline No & 0 & 1,870 & 99.6 \\
\hline
\end{tabular}

mation (for example nutrient, fat, or caloric content), nor was the scientific suggestion followed to mark healthy entrées with a symbol marked (e.g., healthy food symbol, "healthier choice" tag) or a keyword (such as "low-calorie" or "low-fat") (Table 2). In accordance with the study methodology, the individual components of each meal were then assessed for nutritional value. According to the definition given by Krukowski et al. (20), 81\% of all the main components in the meal were rated as unhealthy. None of the 1,877 meals used wholegrain products. In terms of side dishes, steamed or boiled vegetables (carrots, peas, beans, etc.) or salads were offered in a third of all cases. In some cases, the meal also included - almost exclusively sweetened - fruit as a dessert (Table 2). In 5\% of all cases, explicit reference was made to the option to swap the side dish, giving parents and children the opportunity, for example, to replace French fries with steamed potatoes or rice.
Our analyses also show that including a drink automatically or the option of having a free refill for soft drinks is extremely unusual in Germany (Table 2). As a rule, desserts are also usually ordered from the main menu and it is rare that they are included automatically in the meal. Similarly unusual is the use of cartoon characters and product logos on children's menus and giving away of promotional toys (Table 2).

The resulting total score values were almost normally distributed over a range of -3 to +6 . The arithmetic mean of the 1,877 score values was $0.73 \pm 0.85$. In addition to this, a positive correlation was found between the price of the food and its quality; accordingly, at the restaurant level of analysis, a higher price was accompanied by a higher score value $\left(\mathrm{r}^{2}=0.275 ; \mathrm{p}<0.001\right)$. Further analyses, which are not depicted here, showed that, on average, the score value increased from $0.73 \pm 0.85$ to $1.23 \pm 1.64$ ( $p>0.05$ ), when the price exceeded $€ 10$ (as of 1 July 2019 , this is equal to $\$ 11.29$ or $£ 8.93$ ). The separate validation sample showed that $81 \%$ of all restaurants posted their menu online.

\section{DISCUSSION}

\section{Principal Findings in the Light of Current Research}

What German children adolescents are served in restaurants appears to be unbalanced and lacking in variety. If we compare the CMA score values with other available studies, the mean value of $0.73 \pm 0.85$ is considerably lower than average scores from $\mathrm{Ca}$ nadian or North American restaurants. An analysis of children's meals in 130 local and chain restaurants in Arkansas, USA (in 2009-2010), resulted in an average CMA score value of $1.3 \pm 1.7$ (20). A 2012 study of 5 fast food restaurants from Santa Clara County, USA, reported an average score value of $1.1 \pm 5.2$ (21). In a study from 2013, the average CMA score for children's meals in 137 sit-down, specialty, fast food and fast-casual restaurants in the Dan River Region, USA was found to be $1.6 \pm 2.7$ (22). To our knowledge, the only other study conducted outside of the USA to use the CMA rating was carried out in Ontario province, Canada, where in 2016174 children's meals from 237 restaurants were rated with an average CMA value of $1.02 \pm 2.27$ (23). In view of this, our study rating 1,877 meals in 500 restaurants is not only by far the most comprehensive study, but also the first using the CMA rating outside the context of chain and fast food restaurants.

This very low score value sums up the bleak and unhealthy range of food on offer in German restaurants in a singular number. The striking expression 'food deserts' describes "areas where residents do not have access to an affordable and healthy diet" (24). In this sense, German restaurants could also be described as 'food deserts' for children and adolescents. These deserts begin and end at the restaurant door.

In light of these concerning findings, it is well worth taking a closer look at what exactly is on the menu. The most common types of meals were dominated by highly processed foods (breaded chicken nuggets, French fries, sausages), which have a higher proportion of low-molecular carbohydrates and processed red meat, as well as also featuring a higher total fat and saturated fat content due to the way they are cooked, such as deep-fat frying. Meat dishes from South Eastern Europe are often found on menus from the Balkan regions (e.g., gyros, souvlaki or bifteki). 
Gyros is typically made from pork, which has a high fat content. Souvlaki and bifteki are made of ground red meat and sometimes filled with a high-fat cheese filling. Unhealthy are also the various sausage dishes on offer (bratwurst, currywurst, bockwurst), as most of these are made from red meat and also have a high fat content. Although red meat is an important source of nutrients such as protein, iron and Vitamin B12, the consumption of processed red meat in particular is also associated with diseases such as bowel cancer, type 2 diabetes and coronary heart disease (25). Meals that included burgers were also rated as unhealthy as they contain both red meat patties and a burger bun, which usually has a high amount of white flour. Furthermore, it was also seen that the above-listed meat dishes were almost always exclusively offered with French fries as a side dish. Last but not least dishes that would otherwise be classed as desserts were often included on the entrée menu; such dishes are not recommended as a main course for children due to their high sugar content (semolina pudding, rice pudding) and/or high fat content (e.g. sweet pancakes) and the accompanying sauces or spreads (nut-nougat spreads, chocolate sauce, jelly) that also contain fat and sugar. Overall, it can be seen that the majority of dishes on offer feature a high energy density while simultaneously having a low nutrient density.

The items from the CMA provide concrete starting points in order to improve the food available for children and adolescents. The division of the CMA into aspects of presentation at the point of purchase and aspects concerning the specific combination and preparation of the meals fits in with the current findings in relation to improving the food environment in the food service industry. A systematic review of community-based interventions indicated that a combination of improving information at the point of purchase (e.g., by using labels such as "good for health", "low in saturated fat" or "healthy dining") and extending the menu to include more healthy alternatives was particularly successful (6).

\section{Limitations of the Study}

Methodological limitations of this study mainly concern the transferability of the CMA score value to the German food service industry, general criticism of the CMA, the exclusive use of website data for reviewing the menus and the fact that fast food and chain restaurants were not included in the study.

Firstly, in Germany almost all meals were offered on the menu without any alternative options. Our study is thus actually able to assess exactly the food that lands on the plates of children and adolescents. In studies from North America, it is often necessary to infer some items in the CMA from average values, as what is on the menu includes several different components and options that allow for numerous variants to be created. In such cases, the CMA thus measures a value derived from the theoretical different options available and not what is actually ordered by the restaurant's younger customers. Nevertheless, these methodological advantages of the KinG study should be considered when comparing our data with other studies.

Secondly, it is important to always consider the operationalization of individual items in the CMA in light of the latest scientific findings. For example, if a $100 \%$ fruit juice is on the menu, this is rated with one point according to the CMA. Although the CMA was developed on the basis of scientific recommendations from the abovementioned official associations, nevertheless, this item can certainly be criticized on account of the juice's high sucrose content without the corresponding fiber, as is commonly present in the fruit juice (26). Furthermore, the provision of toys is rated in the CMA with a one-point deduction. On the one hand, according to a recent study from the USA, the provision of toys is also viewed critically by the majority of parents as these types of gifts often distract children from their food (27). Although such incentives have traditionally promoted less-healthy foods in fast food restaurants, other authors have also pointed out that such incentives could potentially also be used to promote healthy choices (17). However, this problem seems to be insignificant in Germany as our study found that fruit juice was only included in the meal once and toys were included in 7 cases.

Thirdly, our data does not allow for any conclusions to be drawn about the amount of food served, nutritional value or number of calories per portion. It also does not capture children's actual ordering and consumption behaviour, which should be a focus of future studies.

Fourthly, fast food and chain restaurants were excluded from the sample group. As these restaurant chains feature a very similar range of products and policies all around the world, it is recommended to refer to literature on kids' menus in major fast food restaurants.

The strengths of this study include the national approach to sampling and the strictly differentiated and meticulous data capture procedure. To our knowledge, this study is the first to evaluate the quality of children's meals served in restaurants outside the USA. It requires considerably less effort to investigate so-called "kids' meals" within globally-operating fast food and chain restaurants as all the relevant information and meal combinations are available publicly, for example, via the Internet. In contrast, for the present study, it was necessary to identify and evaluate every single meal in every single restaurant, which made this study considerably more laborious.

\section{CONCLUSION}

Our study suggests two different approaches to improving children's food environment, which should be coordinated to achieve the optimum effect.

Firstly, including more information on the menu can help make decision-making processes easier. For example, a recent study from the USA shows that the selection of a meal represents a complex process of negotiation between parents and children (27). Measures to help promote "healthier decisions" could include indicators about particularly recommended meals and nutritional information. Intervention studies from Canada and the USA show, for example, that simply by including purely nutritional information (in the form of indicating calorie and sodium content on the menu) led to orders having a lower calorie content (16, 28). More recent studies confirm the influence of menu labels to indicate calorie information in decision-making processes (29). On the one hand, the recommendation to depict all dishes in an attractive manner helps children who often choose tried and tested favourites (French fries, pasta) if they cannot read and/or find it difficult to picture what is actually being served when it is described as "Wholegrain pancakes with Mediterranean vegetable filling" or "Vegetable ratatouille with a turret of brown rice". On 
the other hand, this also makes it easier for parents to make a "healthy decision".

Secondly, the quality of the dishes on offer can be improved by changing the menu and using new recipes. After all, the currently one-sided range is not only unhealthy per se, but also promotes food neophobia in the long-term (described as a reluctance to eat and the avoidance of new foods) (4).

Our findings show that opportunities to improving children's food environment are clearly being missed in Germany as children receive nothing but a bleak serving of monotony. There is clearly an urgent need for intervention.

\section{Acknowledgements}

We would like to thank Philipp Kadel, M.Sc. Psychology (Mannheim University, Germany), for his support of this research and for creating tables and figures. We also acknowledge the support by Leona Przechomski, B.Sc. Psychology (Mannheim University, Germany), for her field work within the validation study.

\section{Conflict of Interests}

None declared

\section{Authors' contributions}

SS, J H-K, and LR drafted the manuscript, SS coordinated the publication process, LR contributed the primary data, LR and SS analyzed them, revised and edited the paper. All authors read and approved the final manuscript.

\section{REFERENCES}

1. Schneider S, Diehl K, Görig T, Schilling L, De Bock F, Hoffmann K, et al. Contextual influences on physical activity and eating habits - options for action on the community level. BMC Public Health. 2017;17(1):760. doi: 10.1186/s12889-017-4790-x.

2. Schienkiewitz A, Brettschneider A, Damerow S, Schaffrath Rosario A. Overweight and obesity among children and adolescents in Germany. Results of the cross-sectional KiGGS Wave 2 study and trends. J Health Monitor. 2018;3(1):15-22.

3. Kurth BM, Schaffrath Rosario A. The prevalence of overweight and obese children and adolescents living in Germany. Results of the German Health Interview and Examination Survey for Children and Adolescents (KiGGS). Bundesgesundheitsblatt Gesundheitsforschung Gesundheitsschutz. 2007;50(5-6):736-43. (In German.)

4. Osei-Assibey G, Dick S, Macdiarmid J, Semple S, Reilly JJ, Ellaway A, et al. The influence of the food environment on overweight and obesity in young children: a systematic review. BMJ Open. 2012;2(6):e001538. doi: 10.1136/bmjopen-2012-001538.

5. Rideout K, Mah CL, Minaker L. Food environments: an introduction for public health practice [Internet]. Vancouver: National Collaborating Centre for Environmental Health; 2015 [cited 2020 Mar 24]. Available from: http://www.ncceh.ca/documents/evidence-review/food-environmentsintroduction-public-health-practice.

6. Valdivia Espino JN, Guerrero N, Rhoads N, Simon N, Escaron AL, Meinen A, et al. Community-based restaurant interventions to promote healthy eating: a systematic review. Prev Chronic Dis. 2015;12:140455. doi: $10.5888 /$ pcd12.140455

7. Ayala GX, Castro IA, Pickrel JL, Williams CB, Lin S, Madanat H, et al. A restaurant-based intervention to promote sales of healthy children's menu items: the Kids' Choice Restaurant Program cluster randomized trial. BMC Public Health. 2016;16:250. doi: 10.1186/s12889-016-2892-5.

8. National Restaurant Association. 2017 Restaurant Industry Pocket Factbook [Internet]. Washington D.C.: NRA; 2017 [cited 2020 Mar 24]. Available from: https://www.kisales.com/nra-2017-restaurant-industrypocket-factbook/
9. Moran AJ, Block JP, Goshev SG, Bleich SN, Roberto CA. Trends in nutrient content of children's menu items in U.S. chain restaurants. Am J Prev Med. 2017;52(3):284-91.

10. European Comission. Comprehensive sectoral analysis of emerging competences and economic activities in the European Union. Brüssel: European Comission; 2009.

11. Statistisches Bundesamt. Monthly statistics for the restaurant sector [Internet]. Wiesbaden: Destatis; 2018 [cited 2020 Mar 24]. Available from: https://www.destatis.de/DE/Methoden/Qualitaet/Qualitaetsberichte/Gastgewerbe-Tourismus/gastgewerbe-monatserhebung. pdf?_blob=publicationFile. (In German.)

12. POS Sector. Gastronomy marketing: success with a child friendly restaurant [Internet]. [cited 2020 Mar 24]. Available from: https://pos-sector. de/marketing/gastronomie-marketing-kinderfreundliche-restaurants. (In German.)

13. German Hotel and Restaurant Association. Economic power and job engine - gastronomy and hotel industry. Total expenditure in the out-ofhome-market. Berlin: DEHOGA; 2015. (In German.)

14. Saelens BE, Glanz K, Sallis JF, Frank LD. Nutrition Environment Measures Study in Restaurants (NEMS-R) development and evaluation. Am J Prev Med. 2007;32(4):273-81.

15. Batada A, Bruening M, Marchlewicz EH, Story M, Wootan MG. Poor nutrition on the menu: children's meals at America's top chain restaurants. Child Obes. 2012;8(3):251-4.

16. Hobin E, Lillico H, Zuo F, Sacco J, Rosella L, Hammond D. Estimating the impact of various menu labeling formats on parents' demand for fastfood kids' meals for their children: an experimental auction. Appetite. 2016;105:582-90.

17. Lopez NV, Folta SC, Glenn ME, Lynskey VM, Patel AA, AnzmanFrasca S. Promoting healthier children's meals at quick-service and fullservice restaurants: results from a pilot and feasibility study. Appetite. 2017;117:91-7.

18. The Federation of German Food and Drink Industries (BVE). Annual report 2016/2017 [Internet]. Berlin: BVE; 2017 [cited 2020 Mar 24]. Available from: https://www.bve-online.de/presse/infothek/publikationen-jahresbericht/jahresbericht-2017. (In German.)

19. Schneider S, Hilger-Kolb J, Rüsing L. Obesity à la carte? Children's meal options in German full-service restaurants. Pub Health Nutr. 2020;23(1):102-11.

20. Krukowski RA, Eddings K, West DS. The Children's Menu Assessment: development, evaluation, and relevance of a tool for evaluating children's menus. J Am Diet Assoc. 2011;111(6):884-8.

21. Otten JJ, Hekler EB, Krukowski RA, Buman MP, Saelens BE, Gardner $\mathrm{CD}$, et al. Food marketing to children through toys: response of restaurants to the first U.S. toy ordinance. Am J Prev Med. 2012;42(1):56-60.

22. Hill JL, Olive NC, Waters CN, Estabrooks PA, You W, Zoellner JM. Lack of healthy food options on children's menus of restaurants in the health-disparate Dan River region of Virginia and North Carolina, 2013. Prev Chronic Dis. 2015;12:140400. doi: 10.5888/pcd12.140400.

23. DuBreck CM, Sadler RC, Arku G, Gilliland JA. Examining community and consumer food environments for children: an urban-suburban-rural comparison in Southwestern Ontario. Soc Sci Med. 2018;209:33-42.

24. Cummins S, Macintyre S. "Food deserts" - evidence and assumption in health policy making. BMJ. 2002;325:436-8.

25. Wolk A. Potential health hazards of eating red meat. J Intern Med. 2017;281(2):106-22.

26. Wojcicki JM, Heyman MB. Reducing childhood obesity by eliminating 100\% fruit juice. Am J Public Health. 2012;102(9):1630-3.

27. Anzman-Frasca S, Folta SC, Glenn ME, Jones-Mueller A, Lynskey VM, Patel AA, et al. Healthier children's meals in restaurants: an exploratory study to inform approaches that are acceptable across stakeholders. J Nutr Educ Behav. 2017 Apr;49(4):285-95.e1.

28. Tandon PS, Wright J, Zhou C, Rogers CB, Christakis DA. Nutrition menu labeling may lead to lower-calorie restaurant meal choices for children. Pediatrics. 2010;125(2):244-8.

29. Gruner J, Ohri-Vachaspati P. Food and beverage selection patterns among menu label users and nonusers: results from a cross-sectional study. J Acad Nutr Diet. 2017;117(6):929-36. 